\title{
A Study about Methane Emissions from Different Composting Systems for Coffee By-products on Costa Rica
}

\author{
Macarena San Martin Ruiz ${ }^{1, *}$, Martin Reiser ${ }^{1}$, Gerold Hafner ${ }^{2}$, Martin Kranert ${ }^{1}$ \\ ${ }^{1}$ Institute for Sanitary Engineering, Water Quality and Solid Waste Management, University of Stuttgart, Germany \\ ${ }^{2}$ TTI-Technologie-Transfer-Initiative GmbH, University of Stuttgart, Germany
}

Copyright $\bigcirc 2018$ by authors, all rights reserved. Authors agree that this article remains permanently open access under the terms of the Creative Commons Attribution License 4.0 International License

\begin{abstract}
Throughout the world, agriculture, sanitation and waste management sectors are mainly carried out in isolation, resulting in permanent nutrient drainage and large amounts of greenhouse gas emissions due to inadequate or excessive use of fertilizers. Currently in Costa Rica, after a study of coffee waste treatment practices in conjunction with NAMA Coffee and based on previous studies carried out in the country, certain questions have arisen regarding the practices and management of coffee by-products to produce organic compost. During this study, a methodology to measure the impact of the application of an aerobic treatment technology for coffee by-products was developed and applied. With this method, different techniques of composting were compared regarding their emission of greenhouse gases, especially methane. As a next step, the reasons for the higher emission rates were examined. The emission rates are given in units of $\left[\mathrm{g} / \mathrm{m}^{2} \mathrm{~h}\right]$ and the categorization and emission ranges were obtained according to the type of treatment and movement at the composting piles of each mill visited in the country. Moreover, ranges of emission factor in this article are given in $\mathrm{g} \mathrm{CH}_{4} / \mathrm{kg}$ raw material. The duration of the project was from December 2017 until July 2018. In total 7 mills were visited in the country, divided in 4 cooperatives or mills and 3 private mills (small coffee farms). The methane emissions that have been observed during the different types of treatment applied to the coffee by-products indicate that the conditions must be optimized in order to create high-quality compost without any negative impact on the environment. The results obtained give an overview about five categories of treatment techniques that are used in Costa Rica to convert coffee by-products into compost which is used as a fertilizer. To some of these composting-categories, methane emission factors were calculated. It was found, that depending on the type of treatment, the methane emissions are between 10 times and
\end{abstract}

more than 60 times higher than emission rates at garden waste or bio-waste composting plants referenced in literature. German Agency for International Cooperation (GIZ) established a NAMA support project (NSP): Low-carbon coffee Costa Rica. Within this framework, the actual activities are carried out.

Keywords Greenhouse Gases, Coffee By-products, Composting, Emissions, Coffee Waste Management, Emission Factor

\section{Introduction}

In recent years, composting has become a promising technique for degrading organic residues and producing fertilizer under low operating costs and technology [1]. However, composting plants may generate environmental problems such as gas emissions like methane $\left(\mathrm{CH}_{4}\right)$ and unpleasant odours especially when the decomposition is slow under low $\mathrm{pH}[2,3]$.

Compost Systems can be divided in three different bases and depending on them, the classification can be done according to the oxygen usage (anaerobic and anaerobic), temperature (mesophilic and thermophilic) and according to the technology applied [4]. For this last base, the general classification of different composting systems can be done in two categories: "windrow or pile" ( open system) where the whole system is done in the open in elongated piles (windrows) and "in vessel" ( enclosed system) were the process is done in a reactor [4,5]. For windrow systems there is a subcategorization depending on the aeration method used such as, turned windrow where is the most popular example of a nonreactor system and forced air windrow which an extended aerated pile is used $[5,6]$. For in-vessel systems different techniques can be performed 
either in vertical bioreactors that involves cylindrical containers or tanks and horizontal bioreactors like channels, cells, containers and tunnels [5,7]. Regardless the type of system used in open windrow composting, even if there is a control or not of the exhaust gases produced during the process, windrow composting derivate a challenge for the quantification of the emissions [7].

The first stage of composting is characterized by the self-heating of the organic matter and by its intense decomposition [4-6]. This is due to the existence of large sources of degradable carbon, which result in intense microbial activity that releases heat and increases the temperature of organic matter [8]. For this reason, thermophilic microorganisms predominate in this phase, which work at an optimal temperature of $55^{\circ} \mathrm{C}[4,6]$.

The key parameters for rapid substrate decomposition are sufficient oxygen and moisture [4,7]. Composting processes can be considered as a complex network of physically and chemically influencing, interacting and counteracting parameters [8]. The decomposition of organic matter is carried out by successive microbial populations, i.e. mesophilic microorganisms (which thrive at temperatures between $20{ }^{\circ} \mathrm{C}$ and below $40{ }^{\circ} \mathrm{C}$ ), heat-tolerant species at temperatures up to $50{ }^{\circ} \mathrm{C}$ and thermophilic bacteria, in individual cases at temperatures up to $70{ }^{\circ} \mathrm{C}$ [8]. The interaction of all these parameters results in a dynamic system whose control places stringent demands on process design [8].

Moreover, inadequate air supply leads to incomplete aerobic degradation and therefore to acidification of the compost [12]. In addition, the lack of air means the release of anaerobic metabolites that generate bad odors and leaching [8]. The second phase of composting is carried out under mesophilic temperatures (around $30^{\circ} \mathrm{C}$ ) and is called the maturation phase where macromolecules are degraded by specialized microorganisms [8].

Depending on the amount of air supplied to the micro-organisms they are able to break down the available carbon resources and thus produce carbon dioxide and water [13]. The location of the composting area is of extreme importance to prevent the impacts of greenhouse gas emissions, as well as the control of odors and microorganisms in the air [14].

Regarding coffee, this has been an important worldwide beverage for years and in 1720, the coffee was introduced in Latin America, especially the specie of Coffee Arabica, where right after the coffee arrived in Martinique, Antilles, was sown in Costa Rica in the XVII century [15]. Costa Rica achieved to be the first country during that time and during the XVIII involved in the coffee industry $[11,12]$. The industrialization of coffee is one of the activities that has the greatest environmental impact if there is no control over the production and its processes due to a high amount of organic material in wastewater and coffee pulp residues [17].
The relevance of this industrialization in the country, is that it represents $8 \%$ of the labor work in the country, contributing in turn, $9 \%$ of greenhouse gases (GHGs) emissions [18] .This sector produces three more frequent GHGs: $\mathrm{N}_{2} \mathrm{O}, \mathrm{CO}_{2}$ and $\mathrm{CH}_{4}$ [18]. The importance of the GHGs is that are gases that absorb the heat in the atmosphere [14,15]. They are complex molecules, radiating the heat trapped in the atmosphere back to the surface to another GHG molecule or emitted upward to space $[16,17]$.

The intergovernmental panel on climate change (IPCC) uses the concept of the global warming potential (GWP) to compare the ability of different gases to trap heat in the atmosphere relative to $\mathrm{CO}_{2}$ [23]. The GWP is a comparative measure of specific compounds that have the capacity to absorb infrared radiation as heat in the atmosphere [24]. $\mathrm{CO}_{2}$ is the biggest concern to enhance the greenhouse gas effect $(\mathrm{GHG})$ and climate change followed by $\mathrm{CH}_{4}$, having a GWP of $28[18,20,21]$.

In recent years, the issue of adaptation to climate change has become relevant at the global level, despite international efforts to mitigate GHGs in accordance with the Kyoto Protocol, where the impacts of global warming are known to occur and will increase in the upcoming years $[20,22]$. For this reason, Costa Rica has decided to act promptly, declaring its objective of avoiding net carbon emission and is preparing an integrated climate change strategy to achieve carbon neutrality, so that this complex target can be replicated in other countries [14, 24].

Costa Rica has set itself the goal of becoming carbon neutral by 2021[29]. To reach its ambitious climate targets, the country has put in place extensive strategies and action plans, including Nationally Appropriate Mitigation Actions (NAMAs) in a range of different sectors [18]. NAMA was defined at United Nations Climate Change Conference (COP16) in 2010 in Mexico, as a support project with the advantage of offering tools for mitigation, but also for Adaptation, Food Safety, technical and policy advice to change production and processes practices in different sectors which is the source of $10 \%$ of the country's greenhouse gas emissions [13,24,25].

Currently, some coffee mills in the country are treating their coffee residue to produce compost, where the main material is based on coffee by-products. During wet process these by-products are divided in coffee husk, skin, pulp, mucilage and parchment [32]. Coffee by-products composting must be free of greenhouse gas emissions, as with all aerobic processes.

The carbon dioxide generated is climate-neutral carbon, by definition, for the reason that it comes from biomass $[29,30]$. Methane, Ammonia and Nitrous Oxide are generated under anaerobic conditions that are not part of good composting [34].

For the diagnosis of the status quo and the measurement of greenhouse gas emissions in the country, the personal responsible for 7 mills around the central region of the 
country (only one in the Canton of Pérez Zeledón) were visited to understand and learn about the different practices carried out in the management of the coffee by-products in the country.

The information was given at each mill in tons/year $(\mathrm{t} / \mathrm{y})$ and it was based on the amount of coffee fruit $(62.5 \mathrm{t} / \mathrm{y}$ $50000 \mathrm{t} / \mathrm{y})$, coffee pulp $(46,25 \mathrm{t} / \mathrm{y}-37000 \mathrm{t} / \mathrm{y})$ and fanegas processed $(1$ fanega $=250 \mathrm{~kg}$ coffee berries [35]). In this 2017-2018 harvest, it was processed between 250 fanegas 200000 fanegas). This information was provided by the same people interviewed at each mill and personal from German Agency for International Cooperation GIZ-NAMA coffee project.

The main objective of the research was to develop and apply a methodology to measure the impact of the application of an aerobic treatment technology for coffee by-products on a mill for the harvest season 2017-2018. In addition, to share its ability to reduce GHGs and other environmentally damaging impacts compared to treatment previously applied. On the other hand, a technical proposal for the process to measure emissions on site the coffee treatment area in a mill and a model of technical-scientific accompaniment was designed.

\section{Materials and Methods}

\subsection{Composting Technologies}

Table 1. Classification of the Mills per type of movement

\begin{tabular}{|c|c|c|}
\hline Mills & Type of Movement & Frequency of Movement \\
\hline 1 & Daily & $\begin{array}{c}\text { High-Tech mechanical } \\
\text { movement }\end{array}$ \\
\hline 2 & None & Open field deposition \\
\hline 3 & Intermittent (monthly) & Mechanical movement \\
\hline 4 & Intermittent (weekly) & Mechanical movement \\
\hline 5 & None & Open field deposition \\
\hline 6 & None & Direct Application \\
\hline & $\begin{array}{c}\text { Frequent (every 2-4 } \\
\text { days) }\end{array}$ & Mechanical movement \\
\hline 7 & $\begin{array}{c}\text { None } \\
\text { monthly) }\end{array}$ & Direct application \\
\hline & None & Dechanical movement \\
\hline
\end{tabular}

Within the NSP exists 53 Mills in the country as part of this initiative to reduce emissions and during this project, 7 mills were visited. Each mill has a different procedure to treat the material for composting where additional material of coffee by-products such as sawdust, sugar cane by products (sugar cane filter cake and bagasse), sugar cane ashes, semolina and whey are added. Moreover, the ventilation or aeration in the composting piles vary from daily mechanical movement up to no movement prior deposition of the material into the coffee plantations, including the creation of an open field deposition where the coffee by-products are accumulated from one-two years to lifetime. In table 1, is shown the classification of the mills based on the type of movement and frequency of it. Since in a few mills, more than one type of movement or form of treatment is applied, it can be seen that each mill has his own frequency of movement for composting. The duration of composting process is usually between 2 months with an exception of one mill who normally uses one-year process.

\subsection{Measurements and Data Analysis}

The measurements were carried out on several coffee plantations in Costa Rica at full scale open windrow and open fields. The focus was on whether the different methods of treatment for coffee by-products could be comparable or compatible with each other in terms of gaseous emissions. Therefore, the selection of the measurement method should allow for comparable data on the various types of treatment, as well as methane concentrations. A third consideration for the selection of measuring instruments was the compact design of the instruments for easy transport. The last consideration was the week of composting that each mill was having while the measurements were carried out. Prior to the measurements, in a selected study area the estimation of the duration of the measurements were performed, where the estimation of the duration was considered until the emissions remained permanently constant, therefore, no variation during the measurements could occur. In total the measurements where done along each full scale open windrow of composting at the mills for a period of 5 weeks.

An open upper part sampling hood as it is shown in Figure 1, was used to measure the gas concentration at the coffee by-products composting piles. Using a gas detector device (Multitec 540 from Sewerin $($ ), methane, carbon dioxide, oxygen and hydrogen sulfide concentration are able to be detected [36]. The samplings measurements were carried out by duplicate in all the piles and as its follows:

1. The sampling hood was placed over the composting pile for a period of 10 minutes

2. A hose was introduced in a hole of the sampling hood to collect the inner gas. The upper part was uncover allowing the ambient air to enter and to be mixed inside of the sampling hood and a cooler trap was settled between the hose and the device Multitec 540 to avoid condensation.

3. Reading of the gas concentrations from the device Multitec 540 was done after the period was completed.

4. The reading of temperature during the process was done to follow the behaviour of the microbiological part inside the piles. 


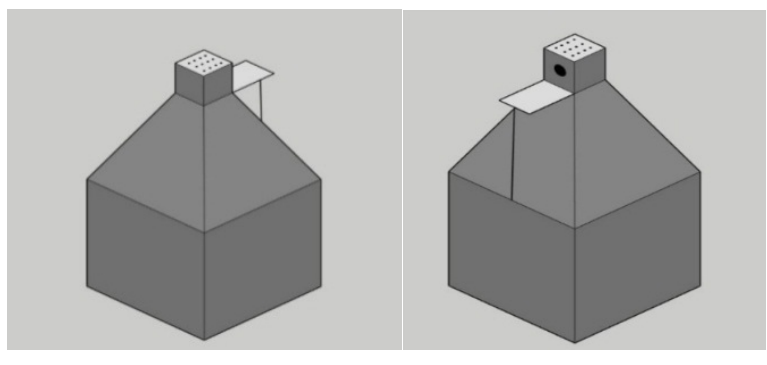

Figure 1. Sampling Hood

\subsubsection{Scientific model for passive area emission sources}

In composting, the sources of passive emission area are relevant and these types of sources were considered for this study [37]. The features presented as passive area emission sources are usually reflected in areas of solid waste, sedimentation, composting piles (with aerobic and anaerobic zones), sludge and wastewater [37].

During sampling, the flow principle passing through the sampling hood at a passive area source was used to extract a defined amount of air (sampling hood), covering the entire area required for sampling as a function of the constant flow of emissions and supply of ambient air. The result is the volumetric flow rate extracted per unit of time [37]. Emission rates are quantified by the principle of flow through the sampling hood, which are related to the treatment and quality of composting.

\subsubsection{Emission Rates}

Once the gas concentration in the streams through the open sampling hood has been obtained, the emission rates can be calculated for all the mills. The emission rates were calculated based on: sampling chamber volume, sampling chamber area, flow volume of the measurement equipment, specific flow rate and correlation factor for each measurement performed. The following equations describes the calculations and formulas used to obtain the emission rates of all the mills.

$$
\mathrm{C}_{\mathrm{CH} 4}=\left(\mathrm{M}_{\mathrm{CH} 4} * \varphi_{\mathrm{CH} 4}\right) / \mathrm{V}_{\mathrm{mo}} 1
$$

$\mathbf{C}_{\mathbf{C H} 4}$ : Methane Concentration, Unit: $\mathrm{mg} / \mathrm{m}^{3}$

$\mathbf{M}_{\mathbf{C H} 4}$ : Molar mass of Methane, Unit: $\mathrm{g} / \mathrm{mol}$

$\mathbf{V}_{\text {mo }} \mathbf{l}: 22,4139 \mathrm{~L}$ at Standard Conditions

$\varphi_{\mathrm{CH} 4}$ : Volume percentage of Methane in air, Unit: ppm For Emission rates:

$$
\mathrm{q}_{\mathrm{CH} 4}=\left(\mathrm{C}_{\mathrm{CH} 4} * \mathrm{~V}_{\mathrm{gas}}\right) / \mathrm{A}_{\mathrm{H}}
$$

$\mathrm{q}_{\mathrm{CH} 4}$ : Emission rate of Methane, Unit: $\mathrm{g} / \mathrm{m}^{2} \mathrm{~h}$

$\mathrm{C}_{\mathrm{CH} 4}$ : Methane Concentration, Unit: $\mathrm{mg} / \mathrm{m}^{3}$

$\mathrm{A}_{\mathrm{H}}$ : Hood area, Unit: $\mathrm{m}^{2}$

$\mathrm{V}_{\text {gas }}$ : Gas Flow volume, Unit: $1 / \mathrm{h}$

\subsubsection{Emission Factors}

Emission factors (EF) are specific emission parameters that relate to a reference variable describing the process. When the measurement data is known from the literature, they allow the source strength of an actual facility to be deduced. In this case, no measurement data is known in the country, therefore a comparison with coffee by-products literature was not possible to realize.

On the other hand, the measurement of the emission rates was done in a composting pile, an open field deposition (open field where the coffee by-products are deposited with and without composting treatment) and an area with direct deposition of the coffee by-products at coffee plantations. The variable reference where the EF is calculated in this research is related to the mass of coffee pulp treated. The EF is calculated as follows:

$$
\mathrm{EF}_{\mathrm{CH} 4}=\left(\mathrm{q}_{\mathrm{CH} 4} * \mathrm{t}_{\text {treat }} * \mathrm{~A}_{\text {treat }}\right) / \mathrm{m}_{\text {treat }}
$$

$\mathbf{E F}_{\mathbf{C H} 4}$ : Emission factor of methane related to the mass of coffee pulp treated, Unit: $\mathrm{g} / \mathrm{kg}$

$\mathbf{q}_{\mathbf{C H} 4}$ : Emission rate of Methane, Unit: $\mathrm{g} / \mathrm{m}^{2} \mathrm{~h}$

$\mathbf{t}_{\text {treat }}:$ Duration time of treatment, Unit: $\mathrm{h}$

$\mathbf{A}_{\text {treat }}$ : Area of treatment (surface area of the emission), Unit: $\mathrm{m}^{2}$

$\mathbf{m}_{\text {treat }}$ : Mass of treated material (mass of coffee pulp at the pile), Unit: $\mathrm{kg}$.

\subsection{Statistical Analysis}

In this study, the samplings were conducted between 8:00 hours and 15:00 hours before each mechanical movement. In total 110 measurements were possible to perform in each pile, obtaining up to 5 replicas among the pile, where in 2 piles methane was not detected. Thereafter, 20 replicas in open field deposition and 10 replicas in direct application were carried out. The data were subjected to one-way analysis of variance ANOVA for Windows, to investigate the correlations between emissions rates and the period in weeks of composting at each pile at different mills. A significance level of $\mathrm{p} \leq 0.001$ for piles, $\mathrm{p} \leq 2,8 \times 10^{-9}$ for open field deposition and $\mathrm{p} \leq 0.0002$ for direct application were used for all mean values.

\section{Results and Discussions}

During the period of measurements one of the mills was taken as a study area, in order to understand the behaviour of the temperature over the composting piles for the period of 5 weeks (Mill 1). In parallel of $\mathrm{CH}_{4}$ measurements, the personal from the mill of the study area measured the temperature twice per day, at the same time, to obtain the daily behaviour of the temperature profile at the composting piles. The following results are described and compared over time of composting treatment regarding the type of material added and the weeks of each pile available in the mill to proceed with the measurements during the harvest of 2017-2018.

The table 2 shows the results of methane emissions over the period of treatment at the different mills in Costa Rica. Each week of treatment was compared with different scenarios and parameters between each other. The results 
of the gas methane in the study area were compared with the rest of the mills around the country visited. Once the results are analyzed from the concentration flows through the open sampling hood, the emission rates can be calculated for the 7 mills.

The emission rates generated in each mill are shown below in the same form as mentioned for the emission concentration. Although different forms of treatment were performed in the study area, the comparison was made in reference to how the study mill normally uses and mixes the material.

Table 2. Methane Emissions over period at the Mills in Costa Rica

\begin{tabular}{|c|c|c|c|c|}
\hline Mills & Weeks & $\begin{array}{c}\mathrm{CH}_{4} \\
\text { [Vol. \%] } \\
\pm \text { SD } \\
\end{array}$ & $\begin{array}{c}\mathbf{E R}^{*} \mathbf{C H}_{4} \\
{\left[\mathrm{~g} / \mathrm{m}^{2} \mathbf{h}\right] \pm \mathrm{SD}}\end{array}$ & $\begin{array}{l}\mathrm{T}^{* *} \\
{\left[{ }^{\circ} \mathbf{C}\right]}\end{array}$ \\
\hline 1 & 0 & $\mathrm{ND}^{* * *}$ & ND & 24.4 \\
\hline 2 & 0 & $0.2 \pm 0.1$ & $1.1 \pm 0.6$ & 37.3 \\
\hline 1 & 1 & $0.1 \pm 0.0$ & $0.6 \pm 0.0$ & 48.8 \\
\hline 5 & 1 & $0.3 \pm 0.1$ & $1.7 \pm 0.4$ & 42.0 \\
\hline 3 & 1 & $3.6 \pm 0.2$ & $20.6 \pm 0.9$ & 57.6 \\
\hline 7 & 1 & $\mathrm{ND}$ & ND & 25.3 \\
\hline 4 & 1 & $0.3 \pm 0.1$ & $1.7 \pm 0.8$ & 43.0 \\
\hline 1 & 4 & $0.4 \pm 0.2$ & $2.3 \pm 0.9$ & 67.4 \\
\hline 5 & 4 & $0.1 \pm 0.0$ & $0.6 \pm 0.0$ & 49.0 \\
\hline 3 & 4 & $0.2 \pm 0.2$ & $1.1 \pm 0.6$ & 35.4 \\
\hline 2 & 4 & $0.1 \pm 0.0$ & $0.6 \pm 0.0$ & 35.1 \\
\hline 6 & 4 & $0.2 \pm 0.1$ & $1.1 \pm 0.6$ & 41.2 \\
\hline 1 & 8 & $0.2 \pm 0.1$ & $1.1 \pm 0.7$ & 40.2 \\
\hline 5 & 8 & $0.1 \pm 0.0$ & $0.6 \pm 0.0$ & 30.2 \\
\hline 3 & 8 & $0.7 \pm 0.2$ & $4.0 \pm 0.9$ & 36.6 \\
\hline 2 & 8 & $0.2 \pm 0.1$ & $1.1 \pm 0.4$ & 37.4 \\
\hline 6 & 8 & $0.2 \pm 0.1$ & $1.1 \pm 0.6$ & 50.3 \\
\hline 7 & 8 & $0.1 \pm 0.0$ & $0.6 \pm 0.0$ & 22.9 \\
\hline 4 & 8 & $0.3 \pm 0.2$ & $1.7 \pm 0.9$ & 43.0 \\
\hline 1 & 52 & $1.1 \pm 0.2$ & $6.3 \pm 0.9$ & 33.5 \\
\hline 5 & 52 & $0.2 \pm 0.1$ & $1.1 \pm 0.6$ & 41.0 \\
\hline 4 & 52 & $0.2 \pm 0.1$ & $1.1 \pm 0.7$ & 34.5 \\
\hline
\end{tabular}

*ER: Emission Rates, ** T: Temperature, *** Not Detected, SD: Standard Deviation

The following temperature graph (Figure 2) is obtained for each day of methane measurement, once a day, where 5 temperatures were measured along the piles and an average of them was calculated from the first week after the formation of the composting piles and continuously until the fourth week. In this figure, it was observed that the process presents temperature irregularities during the weeks of treatment. The composting process could be improved if the following recommendations mentioned below can be considered and implemented for the future harvests.

For the calculations of the emission rates, equations 1 and 2 were used based on the initial results delivered by the Multitec 540 measurement equipment. In the first table, it can be seen how the emission rates vary between mills during the range of weeks that the measurements had to be made in the different treatment piles. This is due to the material conditions and how is treated including the mechanical movement and the type of mixture used.

For instance, on the third mill, additionally of the usage coffee by-products for composting, is used a mixture of 3 different materials ((sugar cane filter cake, bagasse and sugar cane ashes. In this third mill, it can be seen has considerably high emission rates. Further studies must be needed, to associate the high emission rates to the external materials. Moreover, besides of the composting area, the study area possesses an open field deposition where the coffee by-products have been and continues to be deposited in them. Therefore, emission measurements were made in this part of the mill, which corresponds to week 52 shown in table 2.

During the measurements, no mechanical movement in the piles was performed, in order to have the same conditions in the morning and afternoon for effective comparison between them since it was demonstrated that after mechanical movement, methane emission can rise the values up to 10 times. The values of $\mathrm{CH}_{4}$ in general, for all the mills and for the treatment piles in the study area, show the inadequate ventilation due to the formation of undesired anaerobic zones that are formed in the pile generating more $\mathrm{CH}_{4}$.

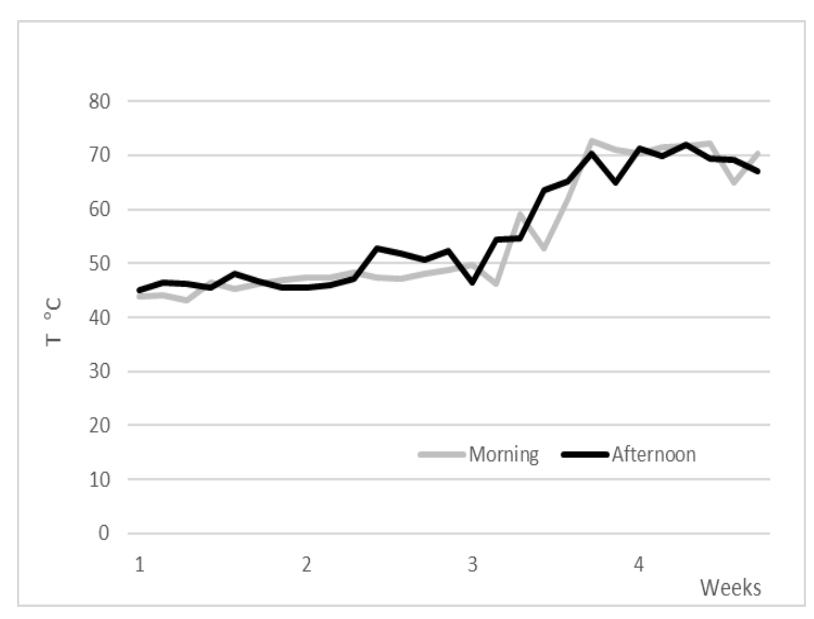

Figure 2. Temperature behavior in Mill 1

The emission rates on open field deposition (Fig. 3), indicates that are stable over time, i.e. have the same shape, color, odor and emission rate. For instance, for open field deposition who has only one year or less, they emit the same amount as a three-year open field deposition? This indicates that over time, the material is not decomposed and degraded, producing continuous emissions of great magnitude in comparison with the rest of the mills and treatments applied in the study area. Therefore, it may be recommended that the best option for coffee by-products 
which are in open field deposition is to proceed with a pre-treatment before deposition.

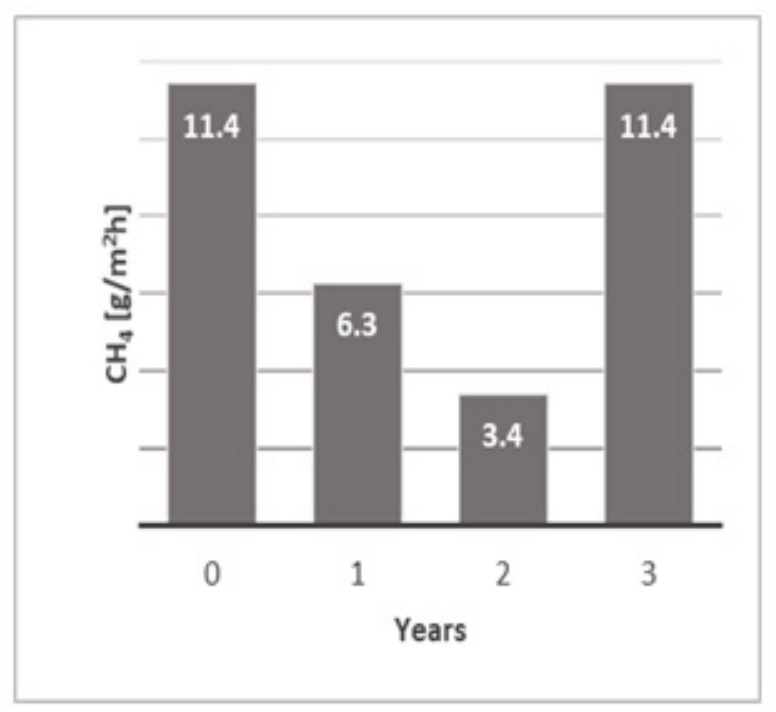

Figure 3. Emission Rates in open field deposition, Mill 1

According to the different treatments of coffee by-products applied in the mills, a classification in 5 main variables was made regarding the type of movement used giving emissions range (ER) values per category:

- Category A: Composting of coffee by-products with high-technology mechanical movement (the usage of a Backhus System).

- Category B: Mechanical movement of coffee by-products for composting

- Category C: Coffee by-products scattered directly on the fields without previous pre-treatment

- Category D: Deposition of untreated coffee by-products in selected sectors other than coffee plantations.

In table 3 , the categorization based on the type movement is shown per mill. Although, category A and B have a mechanical movement, category $A$ has a high-technology movement system (Backhus system), being the reason why it has been designated with a special category. Despite of the fact that are mills that use more than one type of treatment or management technique, the categorization is based on type of movement, reason why one mill can be seen in more than one category. For the case of category $\mathrm{C}$, despite not having any treatment and/or movement prior to its deposition on the farms, they cannot be considered and compared as composting emissions with the rest of the mills. In any case, it has been assigned a category since it is the form or technique that two mills use to manage the coffee by-products, therefore it should be within the categorization, and however its type of movement does not prevail. This table shows all the emission rates from which they were calculated by averaging all the results analyzed during this study by mill, since a range of emissions should be taken as a total of these in a specific area and not by isolated treatments. These ranges are important because depending on the type of treatment applied, the ranges may fluctuate in the tabulated values. This is based on the data calculated according to the results shown above in table 2 .

Additionally, based on emission rates, the table number 3 , shows that categories $\mathrm{B}^{*}$ and $\mathrm{D}$ possess the highest $\mathrm{ER}$. In the case of category $* \mathrm{~B}$, the type of treatment is one of those that produces the greatest amount of emissions which can be influenced for the type of material used to treat the coffee by-product during composting, thus exceeding category $\mathrm{D}$, which corresponds to the deposition or accumulation of coffee by-products for a long period of time (1 year or more). Whether the specific reasons why emissions are produced in such high emission rates are uncertain, one of the reasons may be the type of material applied, the type of treatment and/or movement that is performed, in addition to discontinuous monitoring of the physicochemical parameters throughout the treatment. For the case of the category ${ }^{*} \mathrm{~B}$, the material added is mainly sugarcane by-products where in some studies revealed that from sugar cane byproducts, once the residue is burned, $72 \%$ is being related to methane emissions [38]. This would be one of the reasons of why this specific and centralized way of composting coffee by-products in this mill represents the highest $\mathrm{ER}$, in comparison with the rest of the other mills since they use already material burned and could exist the possibility that the $\mathrm{CH}_{4}$ emissions are coming from the material added to the coffee by-products. Besides of that, the lack of oxygen in the piles and the inappropriate manner of handling composting, indicate $\mathrm{CH}_{4}$ formation in anaerobic zones of the compost pile.

Table 3. Categorization and type of movement applied

\begin{tabular}{|c|c|c|c|}
\hline Category & $\begin{array}{c}\text { Type of } \\
\text { movement }\end{array}$ & Mills & $E R\left[g / m^{2} h\right]$ \\
\hline A & $\begin{array}{l}\text { High-Tech } \\
\text { Mechanical } \\
\text { Movement }\end{array}$ & 1 & $0.6-2.0 \pm 0.63$ \\
\hline \multirow{4}{*}{ B } & \multirow{4}{*}{$\begin{array}{l}\text { Mechanical } \\
\text { Movement }\end{array}$} & 6 & \multirow{4}{*}{$1.0-4.0 \pm 0.43$} \\
\hline & & 2 & \\
\hline & & 4 & \\
\hline & & 7 & \\
\hline *B & $\begin{array}{l}\text { Mechanical } \\
\text { Movement }\end{array}$ & $3 *$ & $21.0 \pm 0.80$ \\
\hline \multirow{3}{*}{$\mathrm{C}$} & \multirow{3}{*}{$\begin{array}{c}\text { Direct } \\
\text { Application into } \\
\text { the fields }\end{array}$} & 7 & \multirow{3}{*}{$0.5-0.7 \pm 0.2$} \\
\hline & & 5 & \\
\hline & & 6 & \\
\hline \multirow{2}{*}{$\mathrm{D}$} & \multirow{2}{*}{ No movement } & 1 & \multirow{2}{*}{$3.4-11.4 \pm 1.0$} \\
\hline & & 4 & \\
\hline
\end{tabular}

For category $\mathrm{A}$ and $* \mathrm{~B}$, a greater number of calculations can be done in comparison with the rest of the mills. Since the category A corresponds to the study area, therefore periodic information was obtained for 5 weeks and for the case of $* \mathrm{~B}$, the personal of the mill provided the necessary 
information to obtain only the results of the day of the measurement. To calculate the absolute emission factor in units of $\mathrm{kg} \mathrm{CH}_{4}$ /raw material, equation 3 was used. The mass of coffee by-products treated in the pile, the area of the pile and the duration of the composting treatment was the necessary information to be determining the emission rates from table 2 .

From all the results obtained in mills $A$ and $\mathrm{B}^{*}$, final averages were made in order to estimate their EF per mill, including all treatments and forms of coffee by-products as well as their depositions in the area, giving a result of EF between 6- $63,5 \mathrm{~g} \mathrm{CH}_{4} / \mathrm{kg}$ raw material. Based on the $\mathrm{EF}$ values obtained in this research, it is possible to make a comparison with literature considering this value as reference of bio-waste composting plants as it is shown in table 3. Costa Rica possess an inventory of GHGs done by the National Meteorological Institute (IMN for its abbreviation in Spanish), therefore the comparison of the values obtained in this research with the values obtain in the National Inventory was necessary.

Table 3. Comparison of emission factors with the literature

\begin{tabular}{|c|c|c|}
\hline $\begin{array}{c}\text { EF values } \\
\text { (g CH} / \mathbf{k g ~ r a w ~} \\
\text { material) }\end{array}$ & Literature & $\begin{array}{c}\text { Range } \\
\text { (g CH} / \mathbf{k g ~ r a w} \\
\text { material) }\end{array}$ \\
\hline 4 & IMN [23] & - \\
\hline 4 & IPCC[24] & $0,03-8$ \\
\hline 2,5 & Amlinger [40] & - \\
\hline 0,5 & Hrad [7] & $0,1-0,9$ \\
\hline $6-63,5$ & A,B,B*,D & $0,1-63,5$ \\
\hline
\end{tabular}

In a future if the country decided to produce a compost using an enclosed system, the values for closed composting treatment in an aerobic digestion plant at high technology, should not exceed $0,1 \mathrm{~kg} \mathrm{CH}_{4} /$ ton, and the range should be between 0,01-0,4 $\mathrm{kg} \mathrm{CH}_{4} /$ ton [39].

It can be observed that the average values and ranges of $\mathrm{EF}$ are higher than the values indicated in the literature, which is presumed to be due to the type of treatment. If both categories $\left(\mathrm{A}\right.$ and ${ }^{*} \mathrm{~B}$ ) indicated in table 3 are compared, where the emission factors are shown, it is evident that category $* \mathrm{~B}$ exceeds the ranges established in the literature by almost 60 times its normal value. It is believed that this is due to the type of material mixture used. To determine more accurately, as it was said before, studies are required to demonstrate that the emissions come from the material added for the treatment.

The coffee by-products, being mixed with sugar cane filter cake, bagasse and sugar cane ashes, might cause certain chemical reactions and additional emissions properly from the material itself, in addition to the problems related to the treatment currently in use, where a high amount of methane is emitted throughout the process. For table 3, the material considered as raw material for this research is considered the mixtures of material of coffee by-products, therefore, the EF are related to them in amount of input in tons of coffee by-product added and treated with the different composting techniques at the mills. After that a comparison with literature based on the range of bio-waste treated in composting systems due to the non-existence of research and values EF related to this field.

In the case of category A, it also exceeds the values, but is closer to the values mentioned in the literature. Lack or excess of ventilation, humidity, type of material added, and temperature may be the possible causes for the high EF values than normal EF. However, it is important to mention that this type of analysis and reference is based on the residual material including different types of aggregate materials and not a single homogeneous material. It would be important for the future to carry out new studies to calculate the emission factors related only to the coffee by-products, to find the unit parameters that affect only one type of material.

Frequent movement of the material results in a desiccation, especially at high outdoor temperatures. As a result, biological degradation processes are interrupted, and the composting process is not complete. No high-quality composting is possible without appropriate humidification and control of important parameters. Further studies are needed to establish an estimated time required for mechanical movement, for example, once a week, once every two weeks, etc. The frequency and regularity of movement will depend on factors such as sufficient air pore volume, moisture content (air to water ratio) and a surface to volume ratio [8].

Unfortunately, nowadays these parameters are not taken into account, where mechanical movement is performed without considering chemical and biological parameters, or when the mill is deemed appropriate without prior analysis of the current conditions of the material to be treated. Unfavorable water content in the decomposition material may partially or completely inhibit the activity and reproduction rate of the microorganisms (dry stabilization). The limits of water content compatible for composting are very wide. These include contents of $25 \%$ to $70 \%$ [41]. In the case of coffee by-products, if its water content is comparatively low in porosity below $20 \%-25 \%$ and above $60 \%$, the aerobic process is stopped. Above $60 \%$, due to the dense structure of the coffee pulp, forced aeration or regular mixing is necessary.

The causes of these situations have a high potential for improvement residues in the management of the treatment process, i.e. there is no optimal waste treatment and the conditions applied during the process are not sufficient to generate quality composting. Some of the problems in the composting treatments observed during this research include:

- Inadequate treatment. No normal composting (very dry, undegraded or very wet fruit, strong ammonia smell, among others) is observed as a final product.

- There is a lack of systematic monitoring of the parameters during the entire composting process, 
such as temperature, $\mathrm{pH}$, humidity percentage, organic matter quantity control, etc. It is important to mention that there is only one monitoring in the mill 1 (study area), however it does not consider all the parameters mentioned,

- It is necessary to strengthen the capacities of the personnel to avoid omissions due to lack of understanding and/or technical knowledge, since many of the mills interviewed incorporated material without having constant relationships and quantities throughout the process, or when it was visually considered to add other materials, water, enzymes or to apply mechanical movement.

- In some cases, the quantities of coffee by-products exceed the amount that can be treated in the area. Therefore, a lack of capacity to monitor waste treatment (in some cases there was a partial amount of untreated material) was observed.

- The use of pesticides to counteract the number of insects, flies and larvae generated during the composting treatment could be avoid if the composting is done under proper conditions.

The above aspects can be reduced by improving the treatment of coffee waste in an appropriate way.

Some recommendations at the work area and for better coffee by-products management are proposed:

- The correct labeling of the treatment area should be made, indicating the days and weeks that the treatment is active. This facilitates the location and the processing time that has been carried out.

- $\quad$ Perform a control of the recommended parameters to be followed, i.e., control of $\mathrm{pH}$, temperature, humidity, etc. to know and understand the behavior of the coffee by products which confirms that the treatment is being performed in the correct way to reduce emissions.

- The third recommendation is having a ventilation control, because this would prevent unwanted anaerobic zones inside of the composting piles, reducing the amount of methane that can be produced from improper waste management.

- The use of a covering membrane for ventilation, humidity and odor control is recommended. It is important to perform moisture control, as mentioned before, the ideal amount of water at the end of the process is in the range of $25 \%-60 \%$ (mass percentage) [41], reason why moisture control is a primary concern, so that the process does not alter the final product and the material does not dry out or become wetter than the recommended value.

- Finally, it is important to bear in mind that more studies must be carried out to demonstrate, by means of analysis, the behavior of this homogeneous material in order to see the feasibility of carrying out large-scale composting in a sustainable manner, obtaining quality composting with low emissions, or to carry out more specific studies to find a different use, such as, for example, animal feed or bio-fuel.

Regarding the accuracy of the results, this cannot be considered as high accurate method, which means that could be twice or half the emissions presented in this report. Further research to find overall EF must be needed to obtain accurate values with all the information needed to proceed and develop a high accurate method.

\section{Conclusions}

It was demonstrated that composting has advantages over simple untreated deposition. The estimated emission factors for different categories related to the type of coffee by-products treatment appear as mass flow over an area and unit of time.

For a GHG emissions balance, these indicative values should be correlated in future studies with the amount of green coffee or the amount of coffee by-product that is produced. For this future assessment, important additional data should be collected, such as type of composting in each mill (with data), co-substrates used, application of composting, waste water management. For a national assessment of emissions in the coffee sector, external effects (transport, fertilizers, energy, chemicals, etc.) should also be considered.

On the other hand, a methodology was developed and applied to measure the impact of an aerobic treatment technology on coffee by-products in the selected study area. It was possible to compare the different treatments in the 7 mills interviewed, being able to obtain a small-scale categorization, based on the type of treatment applied, which are summarized in table 2 , summarizing the emission ranges in units of $\left[\mathrm{g} / \mathrm{m}^{2} \mathrm{~h}\right]$ based on the measurement methodology applied during the 2017/2018 harvest.

Categories $\mathrm{A}$ and $\mathrm{C}$ are shown as having lower emission ranges compared to categories $\mathrm{B}, \mathrm{B}^{*}$ and $\mathrm{D}$, which produce significantly higher emissions. In total, it was found that all the mills produce emissions which are relevant to the climate, having the option of being controlled or halved if the optimum type of treatment is chosen or seeking other options for the use of the coffee material, however more studies are needed for this point.

\section{Acknowledgements}

We acknowledge the support of GIZ, NAMA NSP and ICAFE, for giving the opportunity of this research and for providing all the necessary information to reach the results presented in this article. 


\section{REFERENCES}

[1] J. Barth, "Markets for compost and digestate in Europe Situation, requirements, future development," Eur. Compost Netw., pp. 1-30, 2010.

[2] C. Sundberg et al., "Effects of $\mathrm{pH}$ and microbial composition on odour in food waste composting," Waste Manag., vol. 33, no. 1, pp. 204-211, Jan. 2013.

[3] W. F. Beckerl, "Standard Reference Soils and Sediments," vol. 6, no. 7, pp. 1097-1106, 1994.

[4] Clarence G. Golueke, Composting: a study of the process and its principles - Clarence G. Golueke - Google Books. Minnesota: Rodale Press, 1973.

[5] L. F. Diaz, M. De Bertoldi, and W. Bidlingmaier, Compost science and technology. Elsevier, 2007.

[6] R. T. Haug, The Practical Handbook of Compost Engineering. California, 1993.

[7] M. Hrad, E. Binner, M. Piringer, and M. Huber-Humer, "Quantification of methane emissions from full-scale open windrow composting of biowaste using an inverse dispersion technique," Waste Manag., vol. 34, no. 12, pp. 2445-2453, Dec. 2014.

[8] VDI, "VDI 3575:Emission control Biological waste treatment facilities Composting and anaerobic digestion Plant capacities more than approx. $6.000 \mathrm{Mg} / \mathrm{a}$," Germany, 2003.

[9] R. Afrâa, S. Sushant, and F. Ali, "Assessment of The Composting Process and Compost's Utilizations," 2016.

[10] T. Beffa, "The composting biotechnology: a microbial aerobic slid substrate fermentation complex process," Happyswiss.Com, pp. 1-37, 2002.

[11] C. A. Sierra, S. Malghani, and H. W. Loescher, "Interactions among temperature, moisture, and oxygen concentrations in controlling decomposition rates in a boreal forest soil," Biogeosciences, vol. 14, pp. 703-710, 2017.

[12] "Odor in Commercial Scale Compost: Literature Review and Critical Analysis," 2013.

[13] C. Gougoulias, J. M. Clark, and L. J. Shaw, "The role of soil microbes in the global carbon cycle: tracking the below-ground microbial processing of plant-derived carbon for manipulating carbon dynamics in agricultural systems," J. Sci. Food Agric., vol. 94, no. 12, pp. 2362-2371, Sep. 2014.

[14] VDI, "VDI 3475: Emission control Facilities for biological waste Composting an anaerobic (co-)digestion Plant capacities up to approx. $6000 \mathrm{Mg} / \mathrm{a}$ Ausg.," Germany, 2005.

[15] ICAFE, “Coffee History." [Online]. Available: http://www.icafe.cr/nuestro-cafe/historia/. [Accessed: 03-Aug-2018].

[16] L. Gudmundson, Costa Rica before coffee: Society and economy on the eve of the export boom. Louisiana State University Press, 1986.

[17] Ramirez Cesár; Oliveros Carlos; Juan Sanz, "Lixiviates managment and washing water in the wet Coffee Mill processing," Cenicafé, vol. 66, pp. 46-60, 2015.

[18] "NAMA Facility NAMA Café Costa Rica-A Tool for Low-Carbon Development."

[19] A. Sabljic, Environmental and ecological chemistry. Eolss Publishers, 2009.

[20] EPA, "Overview of Greenhouse Gases," Epa, 2012. [Online]. Available:

https://www.epa.gov/ghgemissions/overview-greenhousegases. [Accessed: 03-Aug-2018].

[21] N. Hopwood and J. Cohen, "Greenhouse Gases and Society," pp. 1-18, 2008.

[22] “Climate and Earth’s Energy Budget,” Jan. 2009.

[23] Green House Protocol, "Global Warming Potential Values (AR5)," Greenh. Gas Protoc., vol. 2014, no. 1995, pp. 2-5, 2015.

[24] M. J. Elrod, "Greenhouse Warming Potentials from the Infrared Spectroscopy of Atmospheric Gases," J. Chem. Educ., vol. 76, no. 12, p. 1702, Dec. 1999.

[25] L. Gustavsson, T. Karjalainen, G. Marland, I. Savolainen, B. Schlamadinger, and M. Apps, "Project-based greenhouse-gas accounting: guiding principles with a focus on baselines and additionality," Energy Policy, vol. 28, no. 13, pp. 935-946, Nov. 2000.

[26] United Nations Framework Convention on Climate Change, Framework Convention on Climate Change. Germany: UNFCCC, 2006.

[27] IPCC, "Climate Change 2014 Synthesis Report Summary Chapter for Policymakers,” Ipcc, p. 31, 2014.

[28] Falt E; Bjørnøy H, "Our Planet: Climate Change and the Cryosphere," UNEP, the magazine of the United Nations-Enviroments Programme, 2007.

[29] J. A. Flagg, "Carbon neutral by 2021: The past and present of Costa Rica's unusual political tradition," Sustain., vol. 10, no. 2,2018 .

[30] T. Unfecc and N. Registry, "The UNFCCC NAMA Registry," no. August 2012, 2015.

[31] unfccc, "NS-72 - NAMA - Low Carbon Coffee - Costa Rica," 2014.

[32] P. Esquivel and V. M. Jiménez, "Functional properties of coffee and coffee by-products," Food Res. Int., vol. 46, no. 2, pp. 488-495, 2012.

[33] W. F. Solutions, "Biomass Carbon Neutrality," pp. 1-24, 2013.

[34] A. Sánchez et al., "CO2 Sequestration, Biofuels and Depollution,” vol. 5, pp. 33-43, 2015.

[35] N. Glover, "Coffee yields in a plantation of coffea arabica var. caturra, shaded by Erythrina poeppigiana with and without Cordia allidora," Costa Rica, 1981.

[36] Sewerin, “Multitec ® 540," 2018.

[37] VDI, "VDI 3880 : Olfactometry Static sampling," Germany, 2011. 
[38] E. B. De Figueiredo, A. R. Panosso, R. Romão, N. La, and S. $\mathrm{Jr}$, "Greenhouse gas emission associated with sugar production in southern Brazil," pp. 1-7, 2010.

[39] A. Groth, C. Maurer, M. Reiser, and M. Kranert, "Determination of methane emission rates on a biogas plant using data from laser absorption spectrometry," Bioresour. Technol., vol. 178, pp. 359-361, Feb. 2015.
[40] F. Amlinger, S. Peyr, and C. Cuhls, "Green house gas emissions from composting and mechanical biological treatment," Waste Manag. Res., vol. 26, no. 1, pp. 47-60, Feb. 2008.

[41] V. Deutscher and I. Anlagen, "VDI 3475: Emission control Mechnical-biological treatment facilities for municipal solid waste," Germany, 2006. 